\title{
Functional properties of different collagen scaffolds to create a biomimetic niche for neurally committed human induced pluripotent stem cells (iPSC)
}

\author{
Krystyna Pietrucha ${ }^{1}$, Marzena Zychowicz ${ }^{2}$, Martyna Podobinska², Leonora Buzanska \\ ${ }^{1}$ Department of Material and Commodity Sciences and Textile Metrology, Lodz University of Technology, Lodz, ${ }^{2}$ Stem Cell \\ Bioengineering Unit, Mossakowski Medical Research Centre, Polish Academy of Sciences, Warsaw, Poland
}

Folia Neuropathol 2017; 55 (2): 110-123

DOI: https://doi.org/10.5114/fn.2017.68578

\begin{abstract}
The biomimetic, standardized conditions for in vitro cultures of human neural progenitors derived from induced pluripotent stem cells (hiPSC-NPS) should meet the requirements to serve as the template and protective environment for therapeutically competent cell population. In this study, two different collagen scaffolds: bi-component consisting of collagen and chondroitin sulphate (Col-CS), and collagen modified by crosslinking agent 2,3-dialdehyde cellulose (ColDAC) have been used for the first time to encapsulate hiPSC-NPs and compared for the ability to create permissive microenvironment enabling cell survival, growth and differentiation. In our previous report, physicochemical comparison of the scaffolds revealed different elasticity, and diverse size and distribution of the pores within the 3D structure. Binary systems of Col-CS and Col-DAC tested in the current study have the correct balance of properties to serve as a biomimetic niche: they accommodate hiPSC-NPs sustaining their ability to proliferate and differentiate into neural lineages. However, a dense, network structure and rounded in shape pores of the Col-DAC microenvironment resulted in differential cell distributions within the scaffolds, with a tendency for augmented formation of highly proliferating cell aggregates as compared to Col-CS scaffolds. In contrast, Col-CS, which exhibited formation of the network of ellipsoidal and inner interconnected parallel pore channels, promoted enhanced cell viability and neuronal differentiation.
\end{abstract}

Key words: collagen scaffolds, chondroitin sulphate, crosslinking by DAC, hiPSC-derived neural progenitors.

\section{Introduction}

Under certain pathological conditions, in which the central nervous system (CNS) microenvironment is altered due to disease-induced stress, infections or trauma, clinically effective therapies are currently lacking [7]. Restoring the function of a damaged brain or spinal cord has always been a challenge due to their limited capacity for regeneration. Stem cell-based therapy opens new opportunities and challenges but is still in its infancy [40], however, when combined with tissue engineering, may result in a spectacular outcome [38]. Numerous tissue engineering strategies have been evaluated for their ability to support reconstruction and regeneration of the nervous system $[10,15,21,23,39]$. Currently, the important approach towards neural tissue

Communicating author

Professor Leonora Buzanska, Stem Cell Bioengineering Unit, Mossakowski Medical Research Centre, Polish Academy of Sciences, 5 Pawinskiego St., 02-106 Warsaw, Poland, phone: +48 226086 449, fax: +48 2266855 32, e-mail: buzanska@imdik.pan.pl 
engineering involves the in vitro culturing of stem cells on a biodegradable and bioactive scaffold to form hybrid tissue-like structures that are feasible for implantation into the injured site of the brain or spinal cord. Such scaffolds must have a stable micro-architecture and suitable biophysical properties. The design criteria for scaffold biomaterial greatly depend on the tissue engineering applications. In neural tissue engineering, proteins, such as collagen (Col) and Col additions: laminin; fibronectin; peptides (e.g., RGD, IKVAV and YIGSR); and polysaccharides, such as chitosan, alginate and hyaluronan are preferred for preparing these scaffolds $[3,33,42]$. These natural polymers contain attachment sites for cell membrane integrins and serve as scaffold receptors, thereby constituting a major recognition system for cell adhesion [15]. Comprehensive data on polymer scaffolding in neural tissue engineering have been published in several excellent review articles [1,3,5,14] indicating that the scaffolds used in tissue engineering must be designed to meet a number of properties. They include hydrophilicity, cell-adhesion and growth, biocompatibility, degradability, adapted pore size and structure, specific surface area, mechanical strength and thermo-mechanical stability [1]. Even small changes in the elastic modulus of the scaffold can affect the differentiation of the neuron, astrocyte, and oligodendrocyte populations [17]. It has also been demonstrated that the scaffold mean pore size greatly affects cellular activity and that subtle changes in the pore size and pore distribution can have significant effects on cell adhesion [20]. To date, creating an engineered construct that perfectly mimics all of the functions of the neuronal extracellular matrix (ECM) has not been successful.

Col, mostly type I, comprises a large portion of the ECM for most tissue types and is widely used as a cellular scaffold biomaterial for tissue engineering. It was found that within biocompatible Col scaffolds, embryonic stem cells differentiate into cells of the neural lineage and express neuronal lineage markers, such as NESTIN and $\beta$-TUBULIN III [19]. The microstructured collagen scaffold with seeded human neural progenitor cells can promote significant neurite outgrowth from dorsal root glia in both 2D and 3D cultures [8] and seems to be an important factor for future repair strategies for traumatically injured nervous tissues. Proteoglycans, including hyaluronic acid (HA) and chondroitin sulphate (CS), in CNS niches, are mainly responsible for providing structural and functional support to neural stem cells but exert different, sometimes contradictory, influence depending upon the niche's physiological context $[4,29]$. In the light of this information, we have asked whether the specific 3D template based on Col functionalized with CS can meet in vitro requirements to sustain neural developmental capacity within the population of neural progenitors derived from human induced pluripotent stem cells (hiPSC-NPs). The scaffold based on Col modified by crosslinking agent 2,3-dialdehyde cellulose (Col-DAC) was also investigated in this study. DAC was selected as the chemically crosslinking agent because it is biodegradable, biocompatible and toxicologically acceptable [11]. Since the capability of the CNS to regenerate depends on the mutual interaction of cells with the in vivo microenvironment, in vitro evaluation of such interactions is required in biomimetic conditions (scaffolds), which resemble a natural stem cell niche. The nature of this interaction is determined by the functional properties of the scaffold as well as the source and type of seeded cells. Human induced pluripotent stem cells (hiPSC) hold great promise for the future application in personalized medicine. Although many cell types have been transplanted into the injured spinal cord and brain tissue, including Schwann cells, olfactory ensheathing glia, activated macrophages, adult neural stem/progenitor cells and mesenchymal stem cells $[19,22,41]$, induced pluripotent stem cells remain incompletely understood and should be further explored.

Recently we have prepared a new three-dimensional (3D) structure Col-based scaffolds, including composite system Col with immobilized chondroitin sulphate (Col-CS) crosslinked by carbodiimide $[28,30]$ and Col cross-linked by DAC [24-26], which could serve as carriers for neural cell cultures. The use of such scaffolds for the maintenance of neural stem cells (NSC) in vitro and in the regeneration of the nervous system has not yet been well studied. In this in vitro study, neurally committed hiPSC seeded within different types of biochemical highly standardized 3D porous Col-CS and Col-DAC scaffolds were examined, evaluated and discussed.

\section{Material and methods \\ Preparation of collagen-based scaffolds}

Col type I was derived from porcine tendon by pepsin digestion and acetic acid dissolution to pre- 
pare a $0.5 \% \mathrm{w} / \mathrm{v}$ dispersion [27]. The characteristic parameters of Col dispersion are as follows: $\mathrm{pH} 3.2$, molecular weight 380,000 and denaturation temperature $(\mathrm{Td})$ of $39^{\circ} \mathrm{C}$.

Bi-component 3D scaffolds consisting of Col and CS were synthesized using a two-stage process: multiple freeze-drying steps followed by 1-ethyl-3(3-dimethyl aminopropyl) carbodiimide hydrochloride (EDC) cross-linking according to the methods described by Pietrucha [28]. In brief, sponge-shape matrices were obtained by freezing the dispersion of Col with CS at $-40^{\circ} \mathrm{C}$. Next, the frozen dispersion was lyophilized at $-55^{\circ} \mathrm{C}$. The crosslinking reaction was carried out by immersing sponges in an ethanol solution containing a mixture of EDC, (morpholino)ethanesulphonic acid (MES) and N-hydroxysuccinimide (NHS). After crosslinking, the sponges were refrigerated at $-40^{\circ} \mathrm{C}$ and subsequently lyophilized at $-55^{\circ} \mathrm{C}$. The synthesis of the Col-DAC scaffold was performed in three steps: (i) preparation of 2,3 DAC by a selective oxidation of cellulose, (ii) construction of the 3D Col sponge-shapes and (iii) cross-linking of Col samples using DAC. A detailed description of the method has been provided previously [24]. 3D porous sponges were incubated in a solution of DAC at $25^{\circ} \mathrm{C}$ for $24 \mathrm{~h}$, at $\mathrm{pH}$ 8.0. The cross-linked Col matrices were then thoroughly washed with deionised water. Finally, the sponge was refrigerated at $-40^{\circ} \mathrm{C}$ and subsequently lyophilized at $-55^{\circ} \mathrm{C}$. Recently, comprehensive biochemical, spectroscopic, morphological and structural properties of those modified Col scaffolds have also been presented $[24,26,28]$.

\section{Cell culture}

Induced pluripotent stem cell culture, neural commitment and differentiation

The iPSC line derived by the episomal system from human CD34-positive fractions of cord blood cells was obtained from Life Technologies (Gibco ${ }^{\circledR}$ Human Episomal iPSC, Thermo Fisher Scientific). The cells were cultured on vitronectin (Thermo Fisher Scientific) and maintained in Essential 8 Medium (Thermo Fisher Scientific), according to the manufacturer's protocol. The medium was replaced every day. As cells reached $\sim 80 \%$ confluence, they were passaged using DPBS without $\mathrm{Ca}^{2+}$ and $\mathrm{Mg}^{2+}$ for washing and $0.5 \mathrm{mM}$ EDTA for detaching from culture vessels every 5 days at a ratio of $1: 6$. The neural commitment of induced pluripotent stem cells was performed according to Yan et al. [44]. Briefly, the iPS cells were seeded onto vitronectin in Neural Induction Medium (Gibco ${ }^{\circledR}$ PSC Neural Induction Medium, Thermo Fisher Scientific) for 7 days. After reaching confluency, cells were passaged on Matrigel (Corning, BD)-coated dishes and expanded as neural stem cells (NSC) in a neural expansion medium (Neural Induction Supplement $1: 50$, Neurobasal and Advanced D-MEM [1:1], Thermo Fisher Scientific). To obtain from hiPS-NSC neural progenitors (hiPSC-NPS) that were more advanced in differentiation, the hiPS-NSCs at passage 6 were used for neuronal and glial differentiation. The cells were seeded at $5 \times 10^{6}$ cells $/ \mathrm{cm}^{2}$ on the Matrigel-covered 6 -well plates in a differentiating medium containing DMEM/F12/Neurobasal (1 : 1, Thermo Fisher Scientific), 1\% FBS, 1\% N2 (Thermo Fisher Scientific), 20 ng/ ml EGF (Sigma-Aldrich), 10 ng/ml bFGF (Thermo Fisher Scientific). Cells were cultured in these conditions for at least 2 weeks, passaged using Accutase (BD) at a ratio of $1: 6$.

\section{Preparation of scaffolds/hiPSC-NPs hybrids}

\section{Sterilization of scaffold samples}

All of the constructed sponges' samples were sterilized using an electron beam (accelerator ELU6Linac) with dose of 18 kGy. Further handling of the scaffolds proceeded under the laminar flow in sterile conditions.

\section{Cell harvesting and seeding on the scaffolds}

Following the process of neural commitment and differentiation, hiPSC-NPs were harvested using Accutase (Corning, BD), centrifuged and seeded in the density of $2.5 \times 10^{6}$ cells $/ \mathrm{ml}$ on the scaffolds placed in the Eppendorf tubes. After 24 hours in the incubator, samples were transferred into 24-well culture plates in fresh medium. Samples were fixed for immunocytochemistry after 6 days of culture in standard culture conditions $\left(5 \% \mathrm{CO}_{2}, 37^{\circ} \mathrm{C}, 90 \%\right.$ humidity).

\section{Viability assay}

To determine the viability of cell culture on the investigated Col-based scaffolds, after 1, 3 and 6 days of culture Col-CS and Col-DAC scaffolds seeded with hiPSC-NPS were washed with warm PBS and placed in a 96-well plate in the Live/Dead ${ }^{\circledR}$ Viability/Cytotoxicity Kit (Thermo Fisher Scientific), using 
$2 \mu \mathrm{M}$ calcein and $4 \mu \mathrm{M}$ EthD-1 solution, according to the manufacturer's instructions. After 30 minutes of incubation, 6 scaffolds per group were measured using FLUOstar plate reader Omega (BMG, Labtech, Germany) at a wavelength Ex 494/Em517 for calcein and Ex528/Em617 for EthD-1. The units used to estimate intensity for the fluorescence are shown as the Fluorescent intensity units (pixels). The conditions of the experiment for each time-point were optimized with the same number of scaffolds and the same number of seeded cells to be comparable between time-points and different scaffolds.

At day 6, living and dead cell distributions in the scaffolds were visualised using Confocal Laser Microscope LSM 510 (Zeiss).

\section{Immunocytochemistry and image acquisition}

Conventional 2D culture and scaffolds with cells were washed with PBS, fixed with $4 \%$ of PFA (15 min), permeabilised with $0.1 \%$ Triton X-100 and blocked with $10 \%$ goat serum. The following primary antibodies were applied overnight: O4 (1 : 100), GalC (mouse IgG3, 1 : 200, Millipore), PDGFRa (1 : 200), NESTIN (1 : 300), NF200 (mouse IgG1, 1 : 400, Sigma Aldrich), GFAP (rabbit polyclonal, 1 : 500, Cappel), $\beta$-TUBULIN III (mouse IgG2a, 1 : 1000, Sigma Aldrich), DOUBLECORTIN (DCX 1 : 500), and MAP-2 (mouse IgG1, 1 : 500, Sigma Aldrich), OCT4 (mouse IgG2b, $1: 200$, Santa Cruz), NANOG (rabbit polyclonal, $1: 200$, Abcam), Ki67 (mouse IgG1, 1 : 500, Leica/Novocastra). After washing with PBS, appropriate secondary antibodies (Goat anti-mouse or Goat anti-rabbit AlexaFluor 488 or AlexaFluor 546, 1 : 1000, Thermo Fisher Scientific) were applied for 1 hour, and cell nuclei were contra-stained with Hoechst 33258. Images were prepared in Laboratory of Advanced Microscopy Techniques, Mossakowski Medical Research Centre Polish Academy of Sciences using Confocal Laser Microscope LSM 510 (Zeiss) with objective: Plan_Neofluar $20 \times / 0.5$ (in Figs. 5-7 we used additional $1.5 \times$ zoom). Scale bars are added as an integral indicator of magnification in Zen Black Edition Software (Zeiss). 3D reconstruction of Z-stack images was performed using the same software.

\section{Statistical analysis}

The results are expressed as mean \pm SD. Statistical analysis was performed using One Way ANOVA, followed by Bonferroni Multiple Comparison Test. The statistical significance of the results was determined for $\left.\left.\left.p<0.0011^{(*)}\right) ; p<0.0001{ }^{(* \star *}\right) ; p<0.00001{ }^{(* * *}\right)$.

\section{Results}

\section{Characterization of hiPS-NSCs and hiPSC-NPs at 2-dimensional culture}

The hiPS cells were used to derive a neurally committed cell population, because of well defined protocol and to avoid ethical concerns: primary human neural stem cell are available only from neurogenic zones of adult brains or from human miscarried embryos. The process of neural stem cell commitment from iPSCs was rapid (7 days of neural induction) and effective (we were able to obtain approximately 20 million of hNSC from one million of hiPSCs). In contrast to hiPSC, the obtained human iPSC-derived neural stem cells (hiPSC-NSC) did not express pluripotency markers OCT4 or NANOG [2], while the multipotent neural differentiation was manifested by expression of markers typical for a neural stem cell population (NESTIN), as well as markers for neuronal ( $\beta$-TUBULIN III, DOUBLECORTIN, MAP-2) and glial differentiation (GFAP, GalC) (Fig. 1A). After further differentiation applied in vitro, neural progenitor population (hiPSC-NPS) was obtained (Fig. 1B). The expression profile of neural markers in hiPSC-NPS was similar to the hiPS-NSC, but the morphology had changed to more typical for neuronal cells, i.e., with long protrusions and small cell body (Fig. 1B). Further, the number of cells expressing MAP-2, $\beta$-TUBULIN III and GalC was significantly higher (Fig. 1B). However, some cells expressing NESTIN in the population of hiPSC-NPs could still be detected.

\section{Three dimensional culture of hiPSC-NPs on modified scaffolds}

\section{Viability, adhesion and distribution of hiPSC-NPs}

In our study, the population of hiPSC-NPs reveals an ability to adhere to and colonize bi-component Col-CS or modified Col-DAC scaffold. Viability of the hiPSC-NPs seeded on Col-CS and Col-DAC scaffolds was evaluated after 1, 3 and 6 days of culture. Living cells were distributed all over both kinds of tested scaffolds (Fig. 2C). The signal coming from living, calcein AM stained hiPSC-NPs was increasing during the culture time in all tested experimental conditions, but a significant rise in viability at 6 DIV (days 

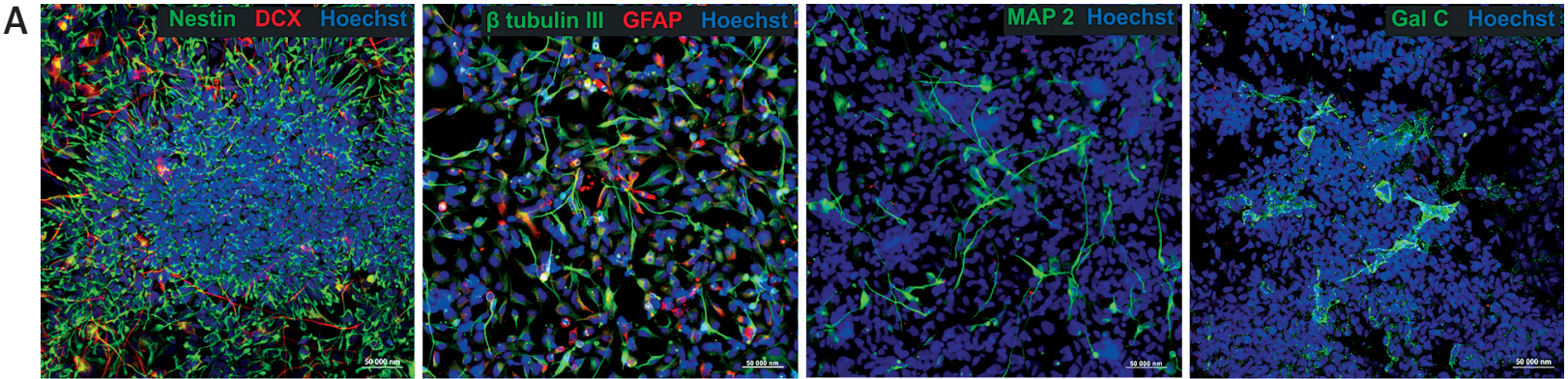

B
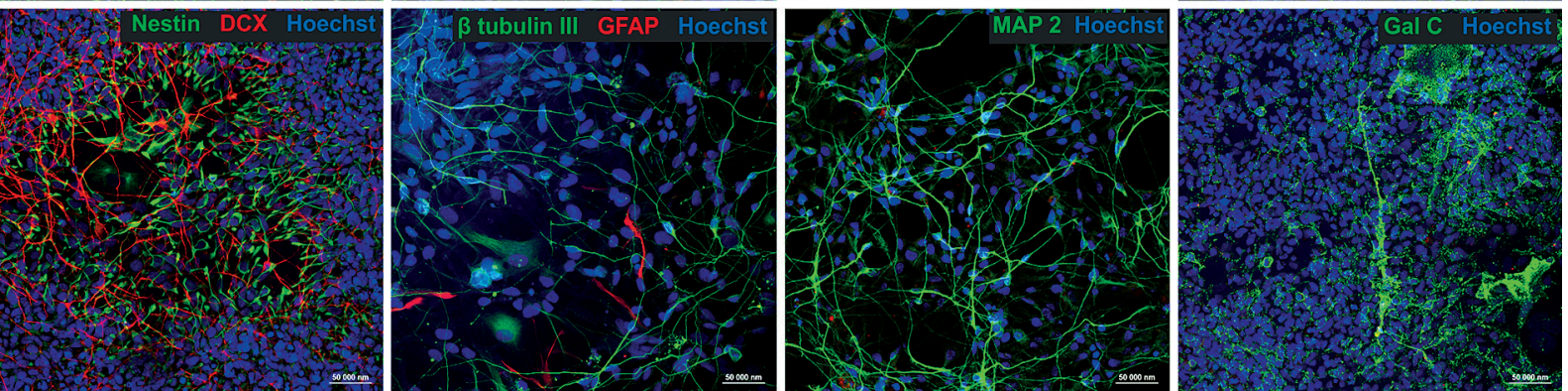

Fig. 1. Human neural stem cell population derived from iPSC (hiPS-NSC) cultured as a monolayer expressed both neuronal and glial markers (A). After prolonged differentiation ( 2 weeks), the expression of neuronal and glial markers in the population of neural progenitors (hiPSC-NPS) was more abundant, however a number of progenitor cells expressing NESTIN were also detected (B). Scale bar is $50 \mu \mathrm{m}$.

in vivo) was revealed only for the cells seeded on ColCS (Fig. 2A). In contrast, the intensity of fluorescence of ethidium homodimer-1 (EthD-1), which labels cells with damaged membranes, was the same for both types of scaffolds. The highest intensity of fluorescence from dead cells was recorded at the first day of the experiment (DIV1) and significantly dropped after DIV1. From day 3 (DIV3) of the experiment, the constant and stable level of cell viability was observed (Fig. 2B). Moreover, at the $6^{\text {th }}$ day of culture we observed only a few dead cells when Z-stacks were measured and visualised (Fig. 2C).

In both types of investigated scaffolds, the cells have been found across the sample, effectively adhering to the inner and outer surface of the scaffolds (Figs. 3 and 4). Seeded cells, depending upon the surface available, were forming: 1) aggregates within smaller pores with proliferating, Ki67 positive cells and at the edges differentiating $\beta$-TUBULIN III positive cells (Figs. 3A and C) or 2) were spreading out to cover the collagen surface of greater pore walls, thus forming a monolayer of cells with flattened and branched morphology (as shown for NESTIN positive cells on Figs. 3B and D). In any case, the population of seeded, hiPSC-NPs was able to penetrate inside the spongy structure of both types of the scaffold (Col-CS or Col-DAC) and populate across the accessible surface. This is illustrated by the confocal Z-stack series of images of Col-DAC (Fig. 4A) and Col-CS (Fig. 4B) samples as well as on their $200 \mu \mathrm{m}$ depth $3 \mathrm{D}$ reconstruction (Fig. 4C), where cells are found at different arrangements (aggregates or spread sheets of differentiated cells). While neuronal marker $\beta$-TUBULIN III is widely present throughout the Z-stack in cells populating both types of scaffolds, astrocytic marker GFAP appears sporadically on Col-CS, compared to a more evident expression on Col-DAC scaffold.

\section{Proliferation of hiPSC-NPs cultured on Col scaffolds}

To estimate the proliferation rate of hiPSC-NPS, the proliferation marker binding to the nuclear proteins of dividing cells - Ki67 was used. The Ki67-positive cells were found predominantly within the cell aggregates/clumps that were placed inside the pores, while the proliferating cells outside the aggregates were only sporadically observed (Figs. 5A and D). Morphologically mature, $\beta$-TUBULIN III positive neuronal cells, with long protrusions aliening longitudinal pockets (pore edges), are in majority post-mitotic (arrows in Figs. 5B, C and F), however few of them were still mitotically active (Ki67 posi- 
A

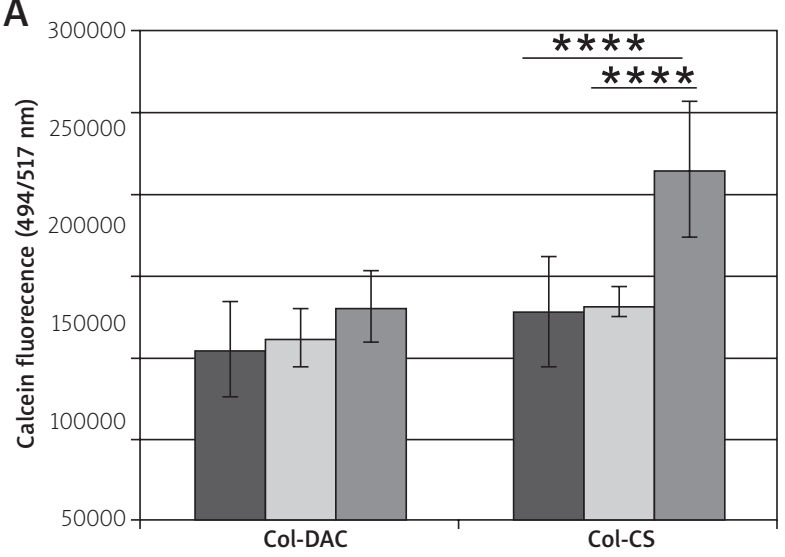

$\mathbf{B}_{2}$

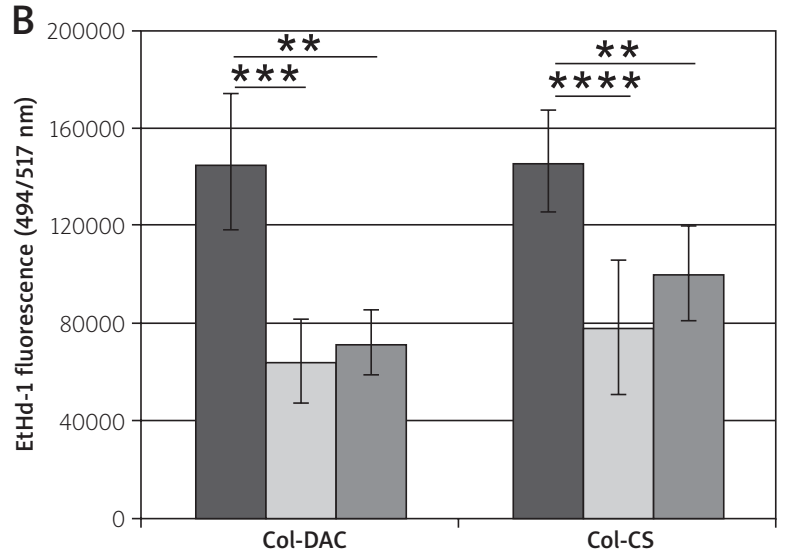

口DIV1 $\square$ DIV3 $\square$ DIV6
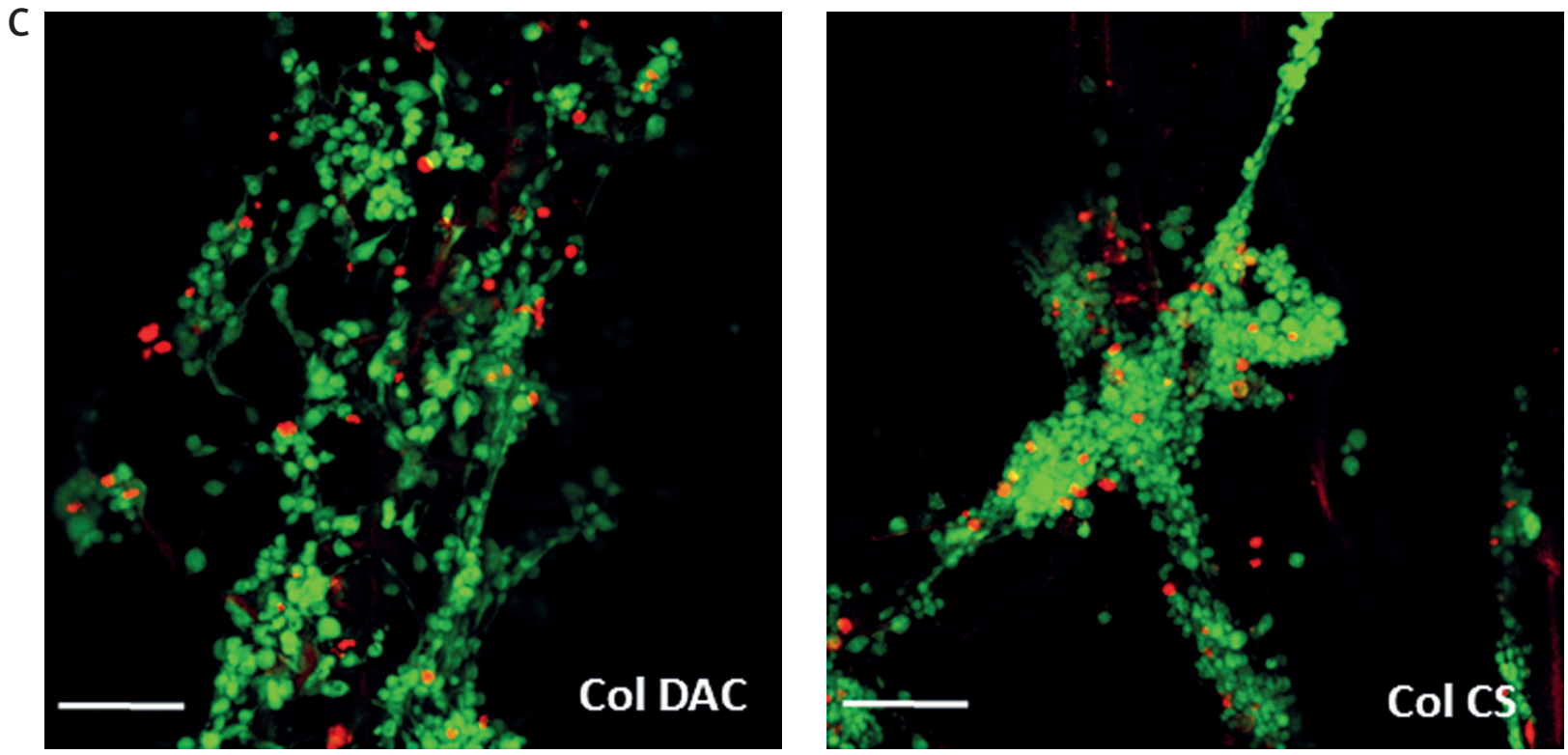

Fig. 2. Viability of hiPSC-NP cells cultured on Col-CS and Col-DAC scaffolds measured at day 1, 3 and 6 of the culture. The calcein-AM staining of living cells (A, C - green cells) revealed the increasing cell number during culture time, statistically significant only for Col-CS, while the EthD-1 fluorescence revealed a significant drop of dead cells after DIV1 and was constant further in the experiment (B, C - red cells). The units used to estimate intensity for the fluorescence are shown as the fluorescent intensity units (pixels) recorded by the FLUOstar plate reader at given wavelength (Ex 494/Em517 for calcein and Ex528/Em617 for EthD-1). Results represent fluorescence intensity (pixels) at the given wavelength from 12 scaffolds for each time point and are presented as mean $\pm \mathrm{SD}, p<0.001\left(^{* \star}\right) ; p<0.0001\left(^{* * *}\right) ; p<0.00001\left(^{(* * *}\right)$. Scale bar is $50 \mu \mathrm{m}$.

tive cells, arrowheads on Figs. 5C, E and F). The exact number of proliferating cells was difficult to determine due to the relatively high autofluorescence of Col-DAC samples in the blue channel (total cell number), but our rough estimation of the percentage of Ki67+ cells resulted in about 38\% for Col-DAC and $33 \%$ for Col-CS, indicating not significant difference between samples.

\section{Differentiation of hiPSC-NPs seeded on the modified Col scaffolds}

The input population of cells used for 3D culture was already pre-differentiated, as described above. It is demonstrated that the seeding process and biocompatible properties of both types of investigated Col scaffolds enabled hiPSC-NPs to sustain their 
COLLAGEN DAC

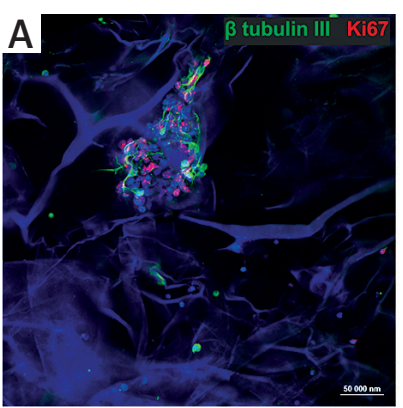

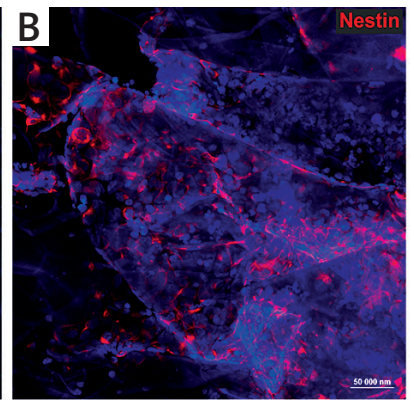

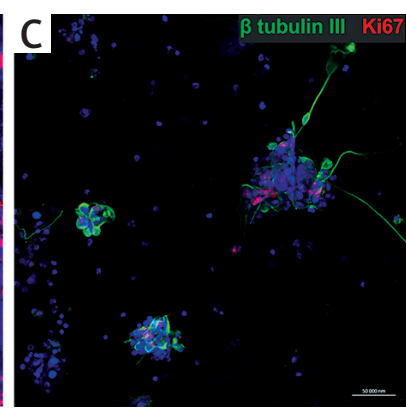

COLLAGEN CS

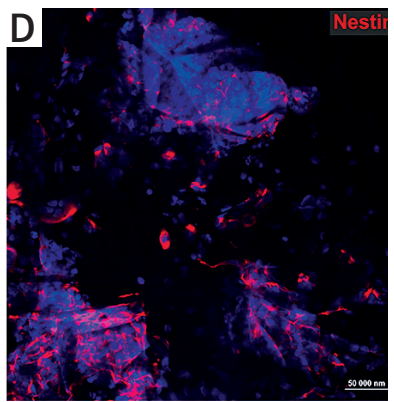

Fig. 3. Cells distribution on the Col scaffolds (DIV6). Cells seeded on Col scaffolds modified by crosslinking with DAC: (A, B) and bi-component Col-CS scaffold: (C, D) stained for neuronal marker $\beta$-TUBULIN III (green), proliferation marker Ki67 (A, C) and for NESTIN (B, D) (red). Cell nuclei are contra-stained with Hoechst (blue). Scale bar is $50 \mu \mathrm{m}$.

morphology and expression of typical markers for neuronal and glial differentiation. The cells within the cell-laden constructs were found mostly as the cell aggregates of different size, as well as monolayers from the cell aggregates, to cover the walls of bigger pores or connecting lamellas (Figs. 4, 5, 6 and 7). Randomly single cells, lacking markers of differentiation were also visible. The porous structure of Col-based scaffolds allows for neurite outgrowth from the cell clumps. We have observed the $\beta$-TUBULIN III positive hiPSC-NPs with neurites that aligned edges of the walls in the pore structure (Figs. 5 and 6B). Within the aggregates or clusters, the neuronal cells expressing $\beta$-TUBULIN III, MAP-2 and DCX were detected as mostly abundant. Neuronal morphology characterized by protrusions extended from the cell bodies was observed on both Col-CS and Col-DAC scaffolds (Figs. 5 and 7). While the differentiated cells appeared predominantly on the edges of the clusters (DCX presented in Fig. 7 and GalC in Fig. 8), cells found in the core of the aggregates were less differentiated (Figs. 7 and 8). In addition, the astrocytic marker (GFAP) was detected among differentiated cells growing in the clusters on both types of scaffolds (Figs. 4 and 7), however to a lesser extent than the neuronal markers. The early glial markers, such as PDGFR $\alpha$ or oligodendrocyte marker Galactocerebroside (GalC) (Figs. 6A, 7 and 8), have also been observed within the cell clusters in both types of scaffolds. The intense scaffold autofluorescence can be detected (blue tissue-like background in the Hoechst channel) after DAC crosslinking of the collagen (Figs. 4A, 5A and 8), while the functionalization of Col with CS gives almost no visible structure of the scaffolds in the fluorescence channels.

\section{Discussion}

In the present study, two types of Col scaffolds have been evaluated: bi-component Col-CS matrices crosslinked by EDC and collagen sponges modified using DAC. DAC was selected as a chemically crosslinking agent because it is biodegradable, biocompatible, and toxicologically acceptable [24]. None of the considered materials, Col, CS or DAC, are ideal for tissue engineering when used alone $[18,28]$. However, a binary system of Col-CS and Col-DAC may provide the correct balance of properties as a biomimetic niche for neural cell culture. In this study we have shown that both types of scaffold can serve as biomimetic niche to accommodate hiPSC-NPs and sustain their ability to proliferate and differentiate into neuronal, astrocytic and oligodendroglial lineages. Col-CS composite scaffolding has been prepared for regenerating in vivo the skin, bone, cartilage and peripheral nerves, yet has rarely been utilized in the restoration of the CNS $[19,20]$. To our knowledge, Col-DAC matrix has never been used to create a biomimetic environment for human neural cell cultures and Col-CS for neural stem/progenitor cells derived from hiPSC.

The hiPSC were applied in this study due to their exceptional features: they can be derived from the adult tissues of the human body and have the ability to differentiate into almost all types of cells [35]. Since they possess great potential for personalized regenerative medicine, they are investigated as a possible therapeutically competent cell population by our [37] and other groups [reviewed in 43]. Neural progenitors (hiPS-NSC) used in this study were derived from human iPSC and seeded on Col-CS and Col-DAC scaffolds for further investigation. The scaf- 

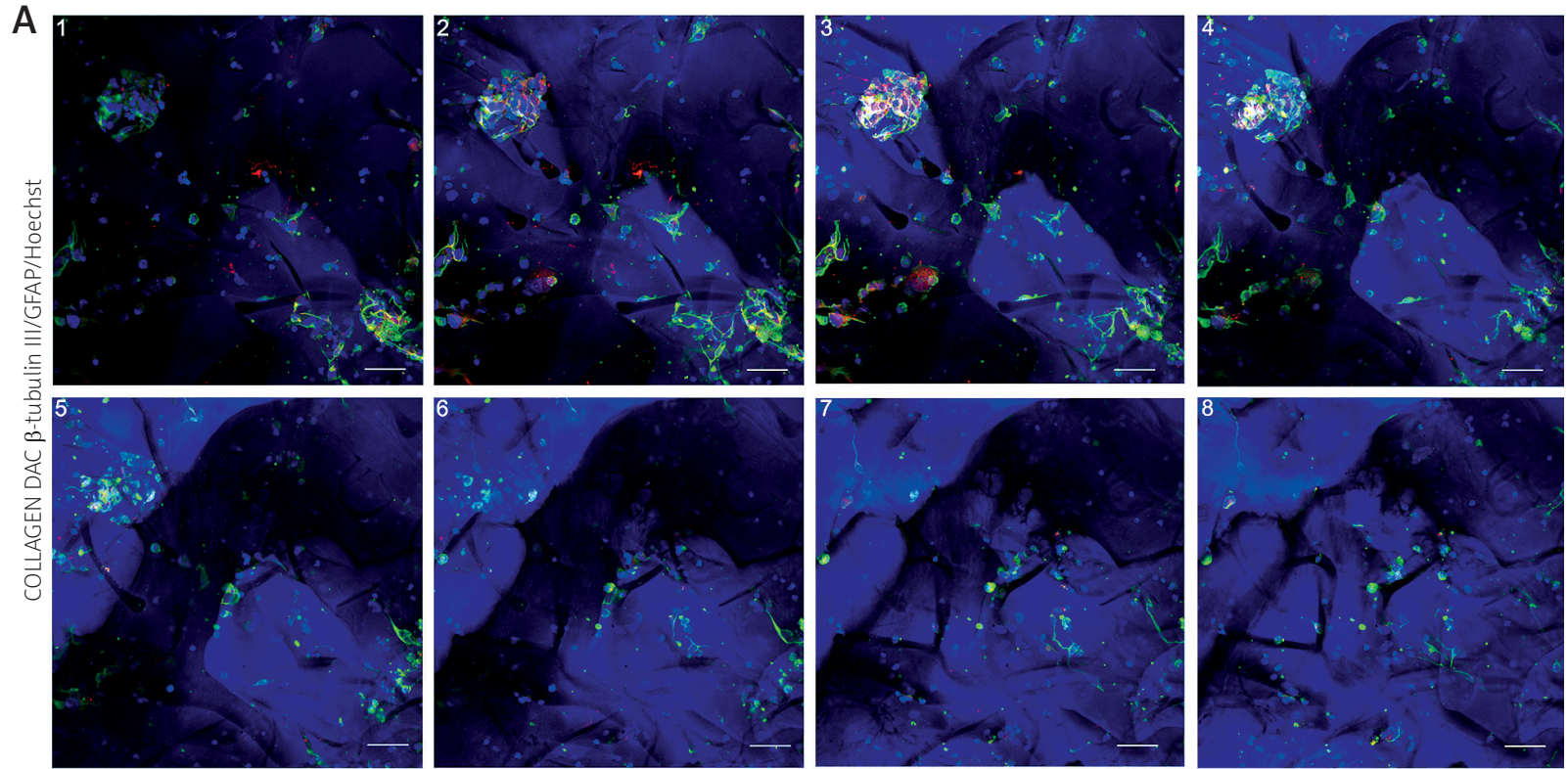

B
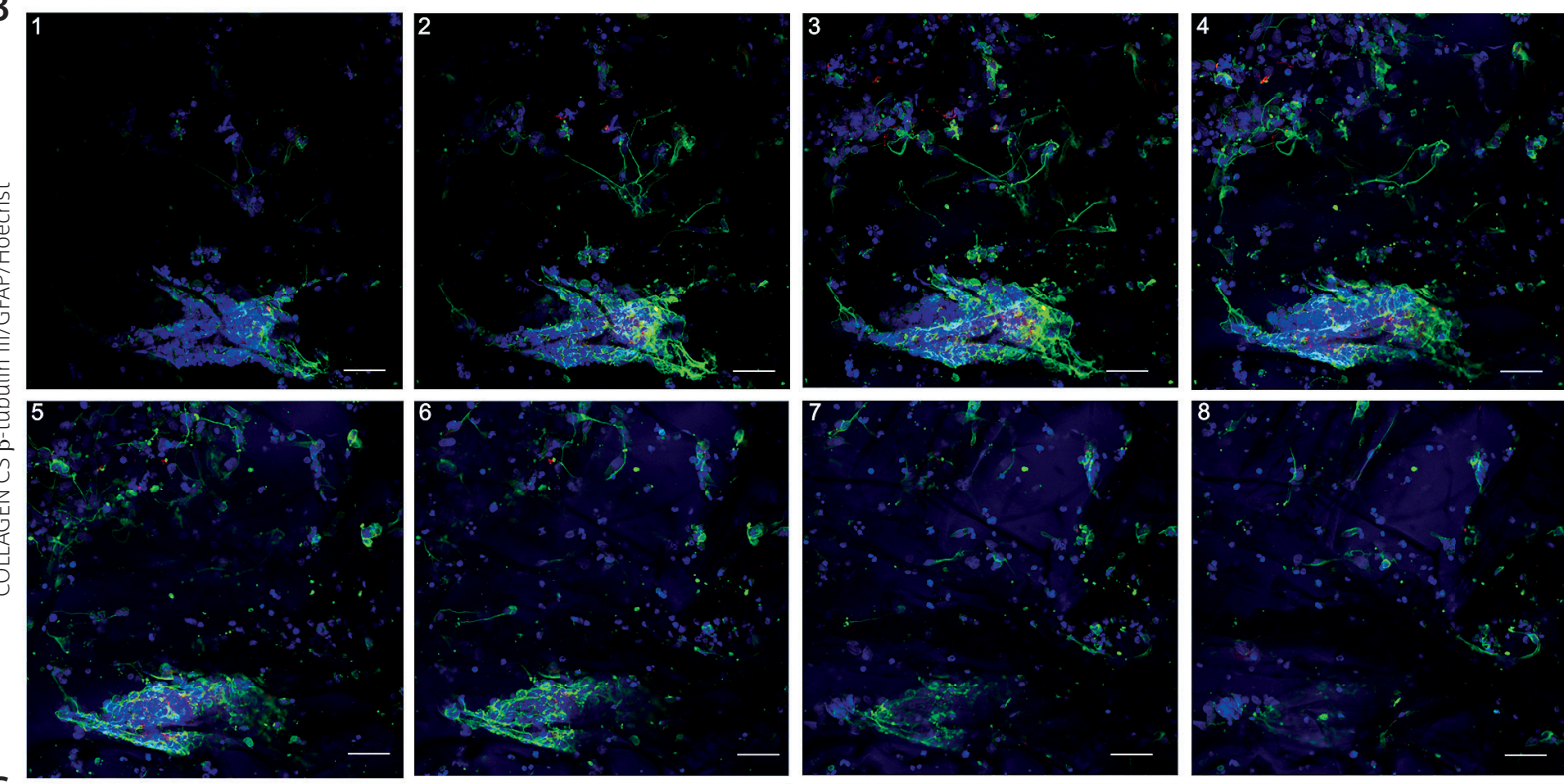

C
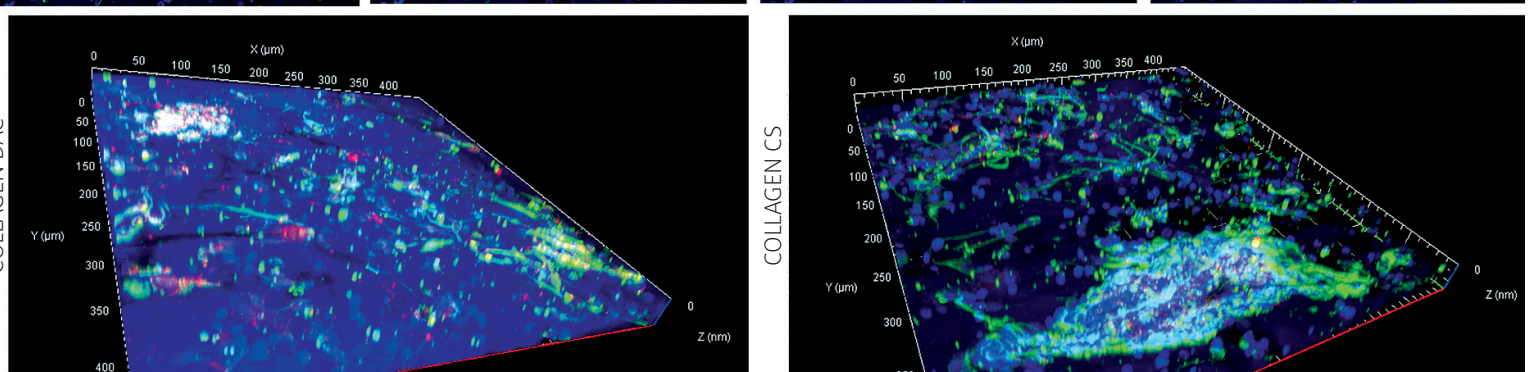

Fig. 4. Cells distribution through the scaffold sample (200 $\mu \mathrm{m}$ Z-stack). Each panel presents 8 subsequent optical sections. Each slice was of about $2.5 \mu \mathrm{m}$ depth, space between slices $25 \mu \mathrm{m}$. Panel A shows distribution of cells seeded on Col-DAC scaffold. Intensive autofluorescence of Col-DAC scaffold was observed. Panel B shows cells seeded on Col-CS scaffold. Panel C shows 3D reconstruction of optical sections presented in A and B. Cells were stained for neuronal marker $\beta$-TUBULIN III (green) and astrocytic marker - GFAP (red). Cell nuclei were contra-stained with Hoechst (blue). Scale bar is $50 \mu \mathrm{m}$. 

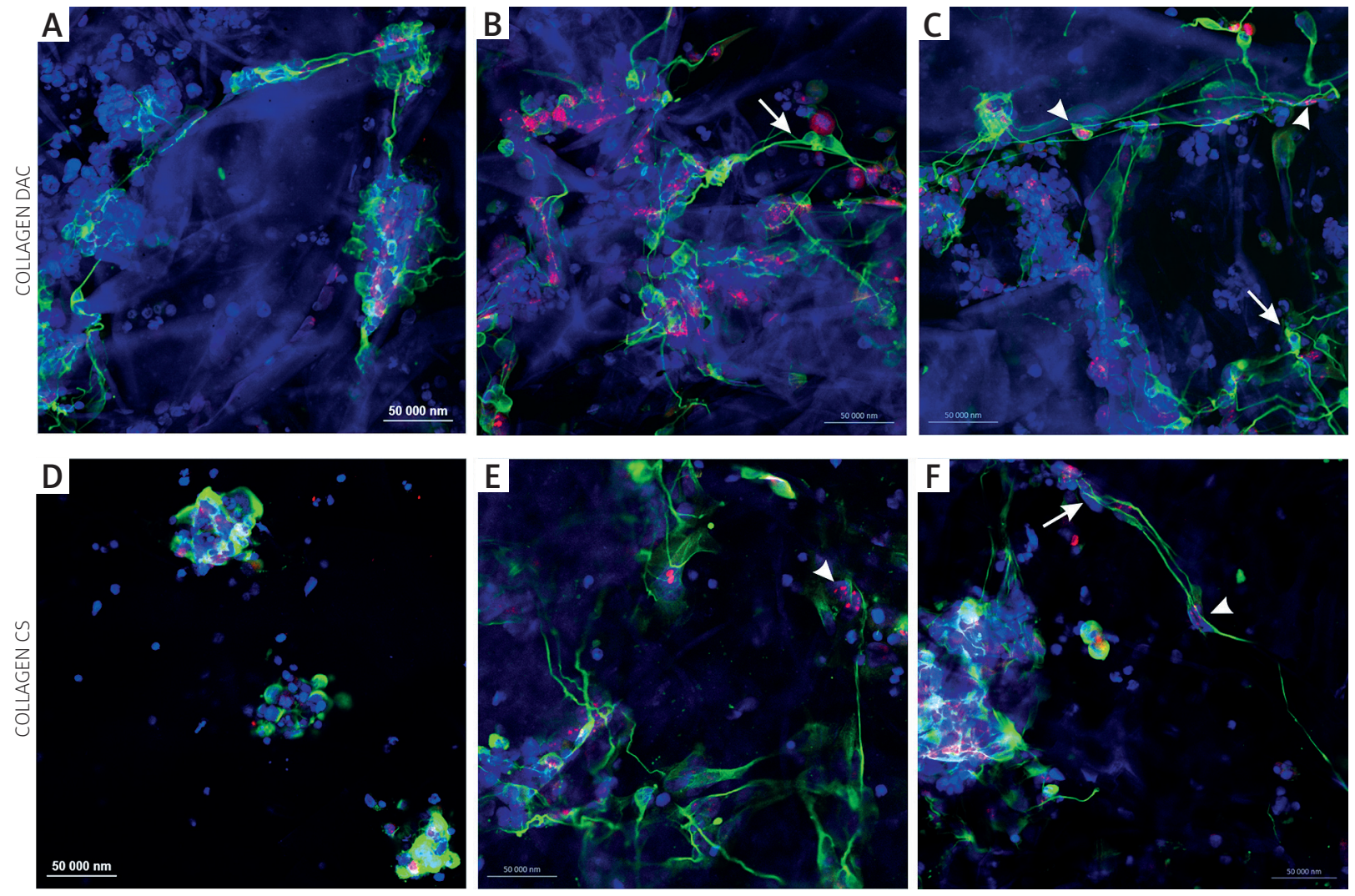

Fig. 5. Proliferation of neural progenitors (hiPSC-NPs) cultured on the Col scaffolds (DIV6): Col-DAC (A, B, C), and Col-CS (D, E, F). The proliferation marker Ki67 (red) is found predominantly within the cell clusters and nearly absent in the cells growing in the monolayer. Morphologically differentiated $\beta$-TUBULIN III (green) positive cells were mainly postmitotic (arrows), however some of the neuron-like cells were still dividing (arrowheads). Scale bar is $50 \mu \mathrm{m}$.
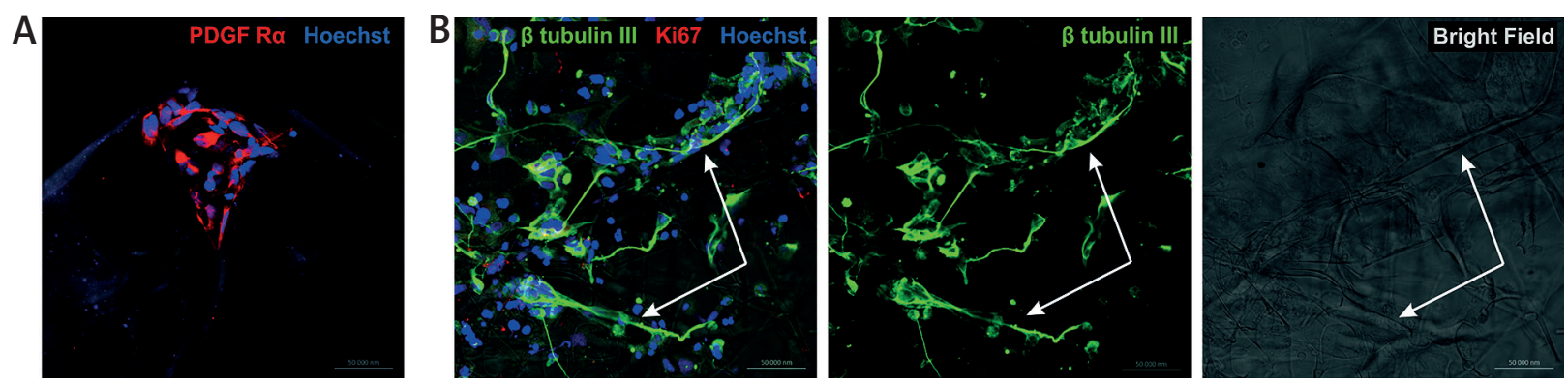

Fig. 6. Alignment of the neural cells protrusions on the porous structure of the Col-DAC scaffold (DIV6). Note the cell clustering in the 'corners' of the scaffold pores (cells stained with PDGFR $\alpha$ ) (A) as well as long protrusions extended from the cell aggregates (B). Arrows indicate the rows/longitudinal pockets (pores) in the scaffold structure and protrusions of neuron-like cells aligning the edges of these pores. Scale bar is $50 \mu \mathrm{m}$.

folds Col-CS and Col-DAC, crosslinked by EDC and DAC, respectively, were shown to immobilize hiPSC-NPs to the active biofunctional surface and allow for their further commitment into three neural lineages: neuronal, astrocytic and oligodendroglial. This is consistent with the study of Drobnik et al. [6] that collagen-based scaffolds using different cross-linking methods were shown to be suitable in elaborateing environments for primary nerve cells isolated from murine embryonic brains.

Both EDC and DAC were selected as chemical crosslinking agents due to their unique properties. 
When a Col-CS sponge reacts with EDC, two essential processes occur, resulting in the formation of Col-Col cross-link and covalent graft CS to the Col backbone without the addition of any toxic catalysts (zero-length EDC) [28]. Finally, 3D semi- and interpenetrating networks are created. The Col-DAC scaffold is formed by a crosslinking reaction between the aldehyde groups $(-\mathrm{CHO})$ of DAC with the free amine $\left(-\mathrm{NH}_{2}\right)$ groups of $\mathrm{Col}$, resulting in a product that is biodegradable, biocompatible and toxicologically acceptable [24].

The viability of human neural progenitors seeded on the scaffolds was measured with the life/dead fluorescent assay and quantitatively evaluated. The significantly increased level of fluorescence indicating living cells show that the cells survive and proliferate (Fig. 2). Interestingly, at day 1 we have observed a significantly higher level of the signal from dead cells as compared to day 3 and day 6 . However it is likely that this difference is artificially elevated by the presence of the cells dying from the seeding and harvesting procedure, not related to the biocompatibility of the scaffolds.

To trace the cellular processes (attachment, proliferation and differentiation - axonal outgrowth) of the hiPSC derived neural progenitors cultured on the scaffolds, immunocytochemical/immunofluorescent marker proteins identification and confocal microscopy analysis were applied. The proliferation rate of the hiPS-NSC cultured on the scaffolds was investigated by immunostaining with Ki67 antibody (Figs. 3 and 5), which binds to the nuclear protein MKI67, present during all active phases of the cell cycle (G1, S, G2, and mitosis), but is absent in resting cells (G0) [34]. Markers applied to detect neural stem/progenitor cells (NESTIN) and their commitment into neuronal ( $\beta$-TUBULIN III, NF200, DOUBLECORTIN, MAP-2), astrocytic (GFAP) and oligodendroglial (PDGFR $\alpha$, GalC) lineages have been used before in the study of our group $[2,36,46]$ and are typical for characterization of neural lineages in vitro and in vivo [31]. It is important to note that the results of this study based on immunofluorescent images are only qualitative due to the high autofluorescence of the Col-DAC scaffolds (Figs. 3A, B, 4A, 5 and 8), which was not the case of Col-CS matrix (Figs. 3B and 4B). The autofluorescence of Col-DAC samples may be assigned to the formation of stable covalent imine bonding between the amino groups of lysine, hydroxylysine and arginine from Col and aldehyde group of
DAC through the Schiff base reaction. As reported in the literature [9], Schiff base compounds containing an imine group $(-\mathrm{RC}=\mathrm{N}-)$ are usually formed by the condensation of a primary amine with an active carbonyl responsible for the fluorescence.

However, the detailed analysis of the confocal microscope Z-stack panels allowed the qualitative assessment for not only the presence of the cells, but also their stage of differentiation, detailed distribution through the scaffold and alignment within the scaffold architecture (Fig. 4). The alignment of the cells in the scaffolds is in accordance with the pore distribution within biomaterial architecture. Cells cover the walls of bigger pores creating a monolayer (Figs. 4, 5 and 6), allowing space for cell protrusions and promote differentiation of hiPSC-NPS, while in the smaller pores and in the edges of the bigger pores cell aggregates are formed. According to our previous results $[24,28]$, the distribution of the pore sizes depends on the type of components and the method of modifying the scaffold. For Col-CS sponges, the largest fraction, at least 55\% of the total pore volume that comprises the sponge is occupied by pores ranging from 20 to $100 \mu \mathrm{m}$ in size, only $25 \%$ of the total pore volume is larger than $100 \mu \mathrm{m}$. Whereas, the sponge-like scaffold Col-DAC had $70 \%$ pores ranging from 20 to $100 \mu \mathrm{m}$. These results agree with those presented by Yannas [45], showing that regenerative scaffolds based on collagen have a narrowly specified pore structure with a pore diameter of 20 to $125 \mu \mathrm{m}$. Such pores are ideal for cell aggregates to adhere and develop a micro-niche. The pore size between $80-100 \mu \mathrm{m}$ of dextran or gelatin cryogels was previously shown to be optimal for stem cells derived from human cord blood adhesion and neural differentiation [12]. Subsequently it was shown that gelatin-based cryogels scaffolds with the pore size ranging from 20 to 120 allow encapsulation of bigger in size mesenchymal stem cells (hUCMSCs) and when supplemented with neuromorphogenes promote their neural differentiation in vitro [32].

In our study, pore size-dependent encapsulation and differentiation of stem cells within spongy collagen scaffolds was confirmed. The hiPSC-NSC are smaller than MSC discussed above, thus the pores about $100 \mu \mathrm{m}$ are suitable for the formation of cell aggregates. The larger amount and specific alignment of pores smaller than $100 \mu \mathrm{m}$ in Col-DAC as compared to Col-CS might promote formation of cell aggregates with proliferative centres (Fig. 3A). 

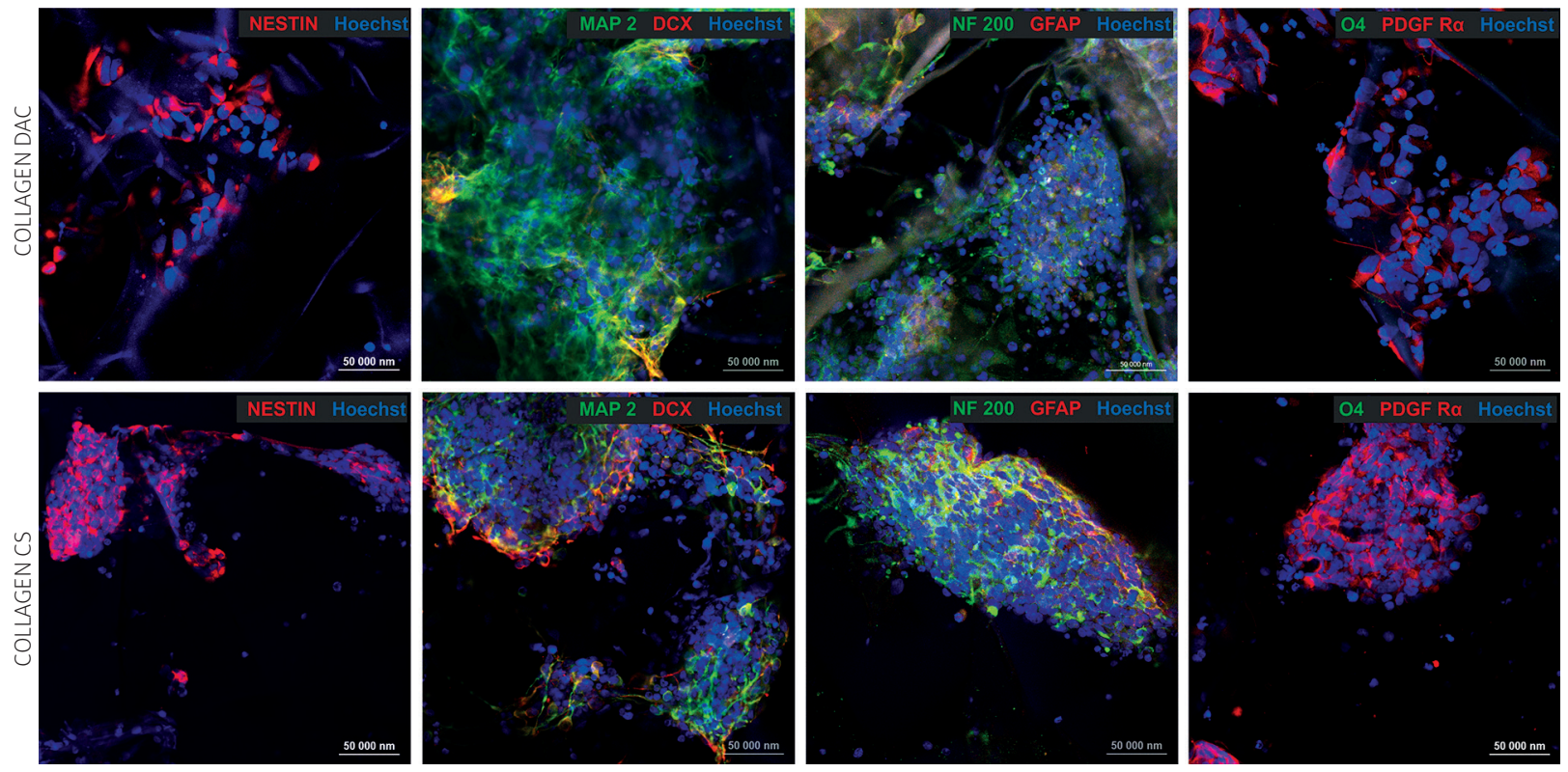

Fig. 7. Neuronal and glial differentiation of hiPSC-NPs cultured on Col-DAC and Col CS scaffolds (DIV6). Some of the cells express markers typical for a neural stem cell population (NESTIN) as well as markers for neuronal (NF200, DOUBLECORTIN, MAP-2) and glial differentiation (GFAP, PDGFR $\alpha$ ). Cell nuclei are contra-stained with Hoechst (blue). Scale bar is $50 \mu \mathrm{m}$.
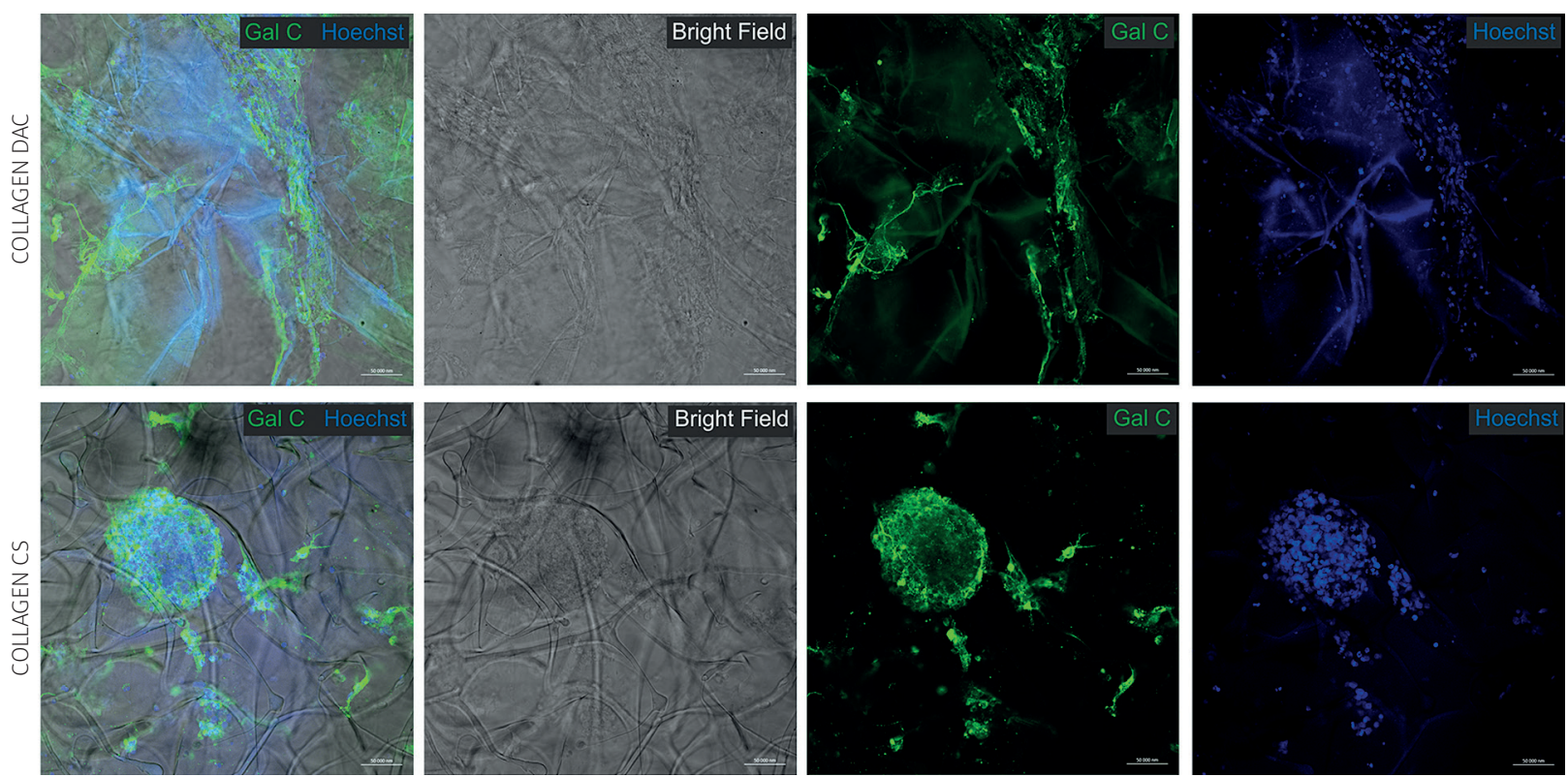

Fig. 8. Oligodendroglial differentiation of hiPSC-NPs cultured on the Col-DAC and Col-CS scaffolds (DIV6). Some of the cells exhibit oligodendroglial marker GalC. Intense scaffold autofluorescence may be observed (blue tissue-like background in the Hoechst channel), after DAC crosslinking of the collagen, while the functionalization of collagen with CS gives almost no visible structure of samples in the fluorescence channels. Scale bar is $50 \mu \mathrm{m}$.

The dual composition of both investigated scaffolds, having smaller and bigger pores, provides an ability to preserve both the proliferative, Ki67-pos- itive, NESTIN-positive population of neural progenitors and the cells committed into different neural lineages. The proliferation marker Ki67 is found 
predominantly within the cell clusters and nearly absent in the cells growing in the monolayer (Fig. 5). The hiPSC-NPs proliferate in the centre of the aggregates, while at the peripheral part they migrate out of the cluster and differentiate predominantly into neurons. As shown in this study, the cells expressing neuronal markers expand protrusions along the pore edges and their interconnecting lamellas. It was earlier noted [31,32] that the pores in Col-CS sponges are ellipsoidal in shape and are oriented parallel to the surface within the sponge, what may influence cell distribution with a tendency to form cell monolayers as compared to aggregates found on Col-DAC. This may explain the preferential appearance of the differentiated cells forming the monolayers on the Col-CS as compared to cell aggregates with defined centres of proliferation on Col-DAC, as revealed by immunofluorescence in Fig. 4. Both types of tested scaffolds allow for the proliferation and further differentiation of neurally pre-differentiated hiPS-NSCS. The seeding population of hiPSC-NPs in 2D conditions revealed markers typical for all three neural lineages, however the porous structure of collagen scaffolds promote/allow neurite outgrowth from the cell clumps supporting further neuronal differentiation, as shown by the expression of DOUBLECORTIN and MAP-2 markers in Col-DAC and Col-CS scaffolds. The astrocytic marker (GFAP), while to a lesser extent than the neuronal markers, was also detected among differentiated cells growing in clusters on both types of scaffolds. The glial markers such as PDGFR $\alpha$ (typical for early glial differentiation) or oligodendrocyte marker GalC, have also been observed at the edges of the cell clusters in both types of scaffold, confirming multilineage potential of differentiation of the encapsulated hiPSC-NPS.

Recently, binary systems more complicated than used in this study, the hybrid scaffolds comprised of collagen, hyaluronic acid, and alginate and additionally functionalized with GRGDSP and Ln5-P4 were shown to support efficient differentiation of hiPSC into neuronal cells [16]. The Col scaffolds tested in this study were stable during the culture time and did not produce any toxic forms of degradation. The surface of tested biomaterial provided proper adhesion and different pore sizes, which immobilised cells in the smaller or bigger aggregates or allowed for cell spreading on the lamella of the Col structures. The encapsulating of living cells inside the scaffold can help to prevent apoptosis caused by induced active inflammation after transplantation of such hybrids into the host nerve tissue [13]. The sustained proliferation and neuronal differentiation capacity of hiPSC-NPs on these modified biomaterials enables further migration from the scaffold or extending protrusions outside the biomaterial into host tissue. The important difference between tested scaffolds was that Col-CS maintain in vitro viable cells significantly longer than Col-DAC. However, we did not observe any significant differences of proliferation and cell differentiation between the two Col scaffolds investigated, therefore this supports the conclusion that using both types of Col-CS and Col-DAC biomaterials in tissue engineering and regenerative medicine is justified, when different physicochemical features are required.

\section{Conclusions}

The Col-based (Col-CS, Col-DAC) binary scaffold systems presented in this study possess appropriate physicochemical properties and are biocompatible, easy to handle and non-toxic. They allow for good cell attachment as well as sustain the proliferation and differentiation capacity of seeded human neural progenitors derived from iPSC. The current study demonstrated that the binary system of Col-CS and Col-DAC scaffolds can be considered as the potential tool for delivery of neural progenitor cells to the injured brain or spinal cord.

\section{Acknowledgments}

This work is supported by the National Science Centre via Grant No. DEC-2011/03/B/ST8/05867 and statutory funds to MMRC.

\section{Disclosure}

Authors report no conflict of interest.

\section{References}

1. Ai J, Kiasat-Dolatabadi A, Ebrahimi-Barough S, Ai A, Lotfibakhshaiesh N, Norouzi-Javidan A, Saberi H, Arjmand B, Aghayan HR. Polymeric scaffolds in neural tissue engineering: A review. Arch Neurosci 2013; 1: 15-20.

2. Augustyniak J, Lenart J, Zychowicz M, Lipka G, Gaj P, Kolanowska M, Stepien PP, Buzanska L. Sensitivity of hiPSC-derived neural stemcells (NSC) to Pyrroloquinoline quinone depends on their developmental stage. Toxicol In Vitro 2017; doi:10.1016/ j.tiv.2017.05.017 
3. Das RK, Zouani OF. A review of the effects of the cell environment physicochemical nano-architecture on stem cell commitment. Biomaterials 2014; 35: 5278-5293.

4. Dityatev A, Seidenbecher Cl, Schachner M. Compartmentalization from the outside: the extracellular matrix and functional microdomains in the brain. Trends Neurosci 2010; 33: 503-512.

5. Donaghue IE, Tam R, Sefton MV, Shoichet MS. Review: Cell and biomolecule delivery for tissue repair and regeneration in the central nervous system. J Control Release 2014; 190: 219-227.

6. Drobnik J, Pietrucha K, Kudzin M, Mader K, Szymański J, Szczepanowska A. Comparison of various types of collagenous scaffolds applied for embryonic nerve cell culture. Biologicals 2017; 45: 1-7.

7. Forostyak O, Dayanithi G, Forostyak S. CNS Regenerative Medicine and Stem Cells. OM \& P 2016; 69-76.

8. Fuhrmann T, Hillen LM, Montzka K, Wöltje M, Brook GA. Cellcell interactions of human neural progenitor-derived astrocytes within micro-structured 3D-scaffold. Biomaterials 2010; 31: 7705-7715.

9. Guo B, Wang LJ, Li BG, Cao XZ, Zhang QS, Li PX. Synthesis and characterization of fluorescent wood pulp cellulose derivative based on Schiff base reaction. Cellulose Chem Technol 2016; 50: 57-63.

10. Hoffman-Kim D, Mitchel JA, Bellamkonda RV. Topography, cell response, and nerve regeneration. Annu Rev Biomed Eng 2010; 12: 203-231.

11. Huang K F, Hsu WC, Chiu WT, Wang JY. Functional improvement and neurogenesis after collagen-GAG matrix implantation into surgical brain trauma. Biomaterials 2012; 33: 2067-2075.

12. Jurga M, Dainiak M. B, Sarnowska A, Jablonska A, Tripathi A, Plieva FM, Savina IN, Strojek L, Jungvid H, Kumar A, Lukomska B, Domanska-Janik K, Forraz N, McGuckin CP. The performance of laminin-containing cryogel scaffolds in neural tissue regeneration. Biomaterials 2011; 32: 3423-3434.

13. Karus M, Ulc A, Ehrlich M, Czopka T, Hennen E, Fischer J, Mizhorova M, Qamar N, Brüstle O, Faissner A. Regulation of oligodendrocyte precursor maintenance by chondroitin sulphate glycosaminoglycans. Glia 2016; 64: 270-286.

14. Khaing ZZ, Schmidt CE. Advances in natural biomaterials for nerve tissue repair. Neurosci Lett 2012; 519: 103-114.

15. Kim H, Cooke MJ, Shoichet MS. Creating permissive microenvironments for stem cell transplantation into the central nervous system. Trends in Biotechnol 2012; 30: 55-63.

16. Kuo YC, Hsueh $\mathrm{CH}$. Neuronal production from induced pluripotent stem cells in self-assembled collagen-hyaluronic acid-alginate microgel scaffolds with grafted GRGDSP/Ln5-P4. Mater Sci Eng C Mater Biol Appl 2017; 76: 760-774.

17. Leipzig ND, Shoichet MS. The effect of substrate stiffness on adult neural stem cell behaviour. Biomaterials 2009; 30: 68676878.

18. Lu D, Mahmood A, Qu C, Hong X, Kaplan D, Chopp M. Collagen scaffolds populated with human marrow stromal cells reduce lesion volume and improve functional outcome after traumatic brain injury. Neurosurgery 2007; 61: 596-602.

19. Michelini M, Franceschini V, Chen SS, Papini S, Rosellini A, Ciani F, Margolis L, Revoltella RP. Primate embryonic stem cells create their own niche while differentiating in three-dimensional culture systems. Cell Prolif 2006; 39: 217-229.

20. Murphy CM, Haugh MG, O’Brien FJ. The effect of mean pore size on cell attachment, proliferation and migration in collagen-glycosaminoglycan scaffolds for bone tissue engineering. Biomaterials 2010; 31: 461-466.

21. Norman LL, Stroka K, Aranda-Espinoza H. Guiding axons in the central nervous system: a tissue engineering approach. Tissue Eng Part B 2009;15: 291-305.

22. Oudega M, Moon LD, de Almeida Leme RJ. Schwann cells for spinal cord repair. Braz J Med Biol Res 2005; 38: 825-835.

23. Pérez-Garnes M, Barcia JA, Gómez-Pinedo U et al. Materials for Central Nervous System Tissue Engineering: Cells and Biomaterials in Regenerative Medicine. In: Eberli D (ed.). 2014 Chapter 7 .

24. Pietrucha K, Marzec E, Kudzin M. Pore structure and dielectric behaviour of the 3D collagen-DAC scaffolds designed for nerve tissue repair. Int J Biol Macromol 2016; 92: 1298-1306.

25. Pietrucha K, Safandowska M. Dialdehyde cellulose-crosslinked collagen and its physicochemical properties. Process Biochem 2015; 50: 2105-2111

26. Pietrucha K. Development of collagen cross-linked with dialdehyde cellulose as a potential 3D scaffold for neural tissue engineering. Int Fed Med Biol Eng Proc 2015; 45: 349-352.

27. Pietrucha K. Effect of irradiation on collagen solutions in relation to biomedical applications. Polym Med 1989; 19: 3-18.

28. Pietrucha K. Physicochemical properties of 3D collagen-CS scaffolds for potential use in neural tissue engineering. Int J Biol Macromol 2015; 80: 732-739.

29. Riquelme PA, Drapeau E, Doetsch F. Brain micro-ecologies: neural stem cell niches in the adult mammalian brain. Philos Trans R Soc Lond B Biol Sci 2008; 363: 123-137.

30. Safandowska M, Pietrucha K. Effect of fish collagen modification on its thermal and rheological properties. Int J Biol Macromol 2013; 53: 32-37.

31. Sarnat HB. Clinical neuropathology practice guide 5-2013: markers of neuronal maturation. Clin Neuropathol 2013; 32: 340-369.

32. Sarnowska A, Jablonska A, Jurga M, Dainiak M, Strojek L, Drela K, Wright K, Tripathi A, Kumar A, Jungvid H, Lukomska B, Forraz N, McGuckin C, Domanska-Janik K. Encapsulation of mesenchymal stem cells by bioscaffolds protects cell survival and attenuates neuroinflammatory reaction in injured brain tissue after transplantation. Cell Transplant 2013; 22 Suppl 1: S67-82.

33. Sarnowska A, Zychowicz M, Buzanska L. Tissue engineering and Bioengineering. In: Neurorestoratology. Volume 1. Huang H, Raisman G, Sanberg PR, Sharma HS (eds.). Nova Science Publisher, Inc., New York 2015; Chapter 8: 187-212.

34. Scholzen T, Gerdes J. The Ki-67 protein: from the known and the unknown. J Cell Physiol 2000; 182: 311-322.

35. Stadtfeld $M$, Hochedlinger K. Induced pluripotency: history, mechanisms, and applications. Genes Dev 2010; 24: 2239-2263.

36. Sypecka J, Sarnowska A. Heterogeneity of local tissue microenvironment influences differentiation of oligodendroglial progenitors. Folia Neuropathol 2013; 51: 103-110.

37. Szablowska-Gadomska I, Sypecka J, Zayat V, Podobinska M, Pastwinska A, Pienkowska-Grela B, Buzanska L. Treatment with 
small molecules is an important milestone towards the induction of pluripotency in neural stem cells derived from human cord blood. Acta Neurobiol Exp (Wars) 2012; 72: 337-350.

38. Tabakow P, Jarmundowicz W, Czapiga B, Fortuna W, Miedzybrodzki R, Czyz M, Huber J, Szarek D, Okurowski S, Szewczyk P, Gorski A, Raisman G. Transplantation of autologous olfactory ensheathing cells in complete human spinal cord injury. Cell Transplant 2013; 9: 1591-1612.

39. Tam RY, Fuehrmann T, Mitrousis N Shoichet MS. Regenerative therapies for central nervous system diseases: a biomaterials approach. Neuropsychopharmacology 2014; 39: 169-188.

40. Tang YH, Ma YY, Zhang ZJ, Wang YT, Yang GY. Opportunities and challenges: stem cell-based therapy for the treatment of ischemic stroke. CNS Neurosci Ther 2015; 21: 337-347.

41. Tetzlaff W, Okon EB, Karimi-Abdolrezaee S, Hill CE, Sparling JS, Plemel JR, Plunet WT, Tsai EC, Baptiste D, Smithson LJ, Kawaja MD, Fehlings MG, Kwon BK.. A systematic review of cellular transplantation therapies for spinal cord injury. J Neurotrauma 2011; 28: 1611-1682.

42. Wang X, Yan C, Ye K, He Y, Li Z, Ding J. Effect of RGD nanospacing on differentiation of stem cells. Biomaterials 2013; 34: 2813 2874.

43. Xie IN, Tang B. The Application of Human iPSCs in Neurological Diseases: From Bench to Bedside. Stem Cells Int 2016; 2016: 6484713.

44. Yan Y, Shin S, Jha BS, Liu Q, Sheng J, Li F, Zhan M, Davis J, Bharti K, Zeng X, Rao M, Malik N, Vemuri MC. Efficient and rapid derivation of primitive neural stem cells and generation of brain subtype neurons from human pluripotent stem cells. Stem Cells Transl Med 2013; 2: 862-870.

45. Yannas V. Emerging rules for inducing organ regeneration. Biomaterials 2013; 34: 321-330.

46. Zychowicz M., Mehn D, Ruiz A, Frontczak-Baniewicz M, Rossi F Buzanska L. Patterning of human cord blood-derived stem cells on single cell posts and lines: Implications for neural commitment. Acta Neurobiol Exp (Wars) 2012; 72: 325-336. 